\title{
Ag Seed-Layer Formation by Electroless Plating for Ultra-Large-Scale Integration Interconnection
}

\author{
Hyo-Chol Koo, ${ }^{*}$ Seo Young Kim, Sung Ki Cho, and Jae Jeong Kim**,z \\ School of Chemical and Biological Engineering, College of Engineering, Seoul National University, Seoul,
} 151-742, Korea

\begin{abstract}
A high density of Pd catalytic particles is an important factor for obtaining a uniform and continuous Ag seed layer in electroless plating. Adequate surface pretreatment is critical for the formation of such a Pd catalytic particle population. In this study, electroless plating of $\mathrm{Ag}$ thin films on TiN substrates was performed using $\mathrm{Sn}$ sensitization and Pd activation as pretreatment methods. Sn surface sensitization improves surface wetting and aids in the formation of a Pd catalytic layer in surface-oxidative Pd activation. The Pd activation supported by Sn sensitization also accelerated the formation of a continuous thin Ag film. Furthermore, a thin Ag seed layer deposited on a patterned structure showed excellent conformality.

(C) 2008 The Electrochemical Society. [DOI: 10.1149/1.2948365] All rights reserved.
\end{abstract}

Manuscript submitted March 26, 2008; revised manuscript received May 29, 2008. Published July 8, 2008.

Because chip size has shrunk in ultra-large-scale integration, resistance-capacitance delay has become a critical factor that limits the overall performance of devices. ${ }^{1} \mathrm{Ag}$ is considered to be the ultimate interconnection material in the metallization process of the semiconductor industry due to its very low resistivity, low diffusivity into silicon, and its high resistance against oxidation. ${ }^{2-4}$

Electroless plating is the autocatalytic process of depositing a metal in the absence of an external source of electric current. In electroless plating, electrons generated by oxidation of a reducing agent on the catalytic surface reduce metal ions. ${ }^{5}$ Once a continuous metal layer is formed, the metal layer itself acts as a catalyst. ${ }^{6-10}$ Electroless plating has high potential for use in the metallization process, especially for the formation of a seed layer for electroplating, due to excellent step coverage, simple processing, low resistivity of the deposited film, and no requirement for an external current supply. ${ }^{11-13}$ Most work in electroless plating has focused on using this method to form a seed layer for complementary metal oxide semiconductor interconnection. However, there have been few reports about bottom-up filling by Ag electroplating. ${ }^{14,15}$ Furthermore, no research investigating the use of an electroless plated $\mathrm{Ag}$ seed layer for bottom-up filling has been done.

In electroless plating, pretreatment steps, where the catalytic particle layer is generated, are very important for obtaining smooth and continuous film morphology. ${ }^{16}$ In this study, Pd is adopted as the catalytic material. Pd activation involves the formation of catalytic Pd particles by the reduction of Pd on the substrate surface using electrons generated by the oxidation of the substrate. To obtain a continuously even $\mathrm{Ag}$ film, a high density of Pd particles is critical. Sn sensitization is a surface-wetting process that improves the hydrophilic character of various surfaces ${ }^{17-23}$ by the adsorption of colloidal particles a few nanometers in size. In one study, after Sn sensitization, the sample was immersed in a solution of Pd ions, and the electron transfer between $\mathrm{Sn}^{2+}$ and $\mathrm{Pd}^{2+}$ generated Pd clusters on Sn colloids. ${ }^{21}$

In Pd activation, the chemical state of the surface is an essential issue because Pd clusters are generally formed by three-dimensional nucleation, which is governed by the interfacial energy between clusters and the substrate. A high-energy interface contributes to the formation of large clusters with low density, ${ }^{24,25}$ which is usually observed on organic-contaminated or oxidized metallic substrates. In Pd activation on TiN substrate, the existence of Ti oxide usually inhibits the formation of high-density Pd particles. ${ }^{1}$

In this paper, electroless plating of $\mathrm{Ag}$ thin films (with thicknesses of $60 \mathrm{~nm}$ ) as a seed layer for electroplating on TiN substrate was conducted using Pd activation. Furthermore, the effect of Sn

\footnotetext{
* Electrochemical Society Student Member.

** Electrochemical Society Active Member.

z E-mail: jjkimm@snu.ac.kr
}

sensitization of the hydrophilic surface prior to Pd activation was investigated. The formation of a seed layer was also tested on a patterned $\mathrm{TiN}$ wafer.

\section{Experimental}

p-Si (100) substrate coated with TiN (metallorganic chemical vapor deposition, $10 \mathrm{~nm}$ )/Ti [physical vapor deposit (PVD), $15 \mathrm{~nm}$ ] as diffusion barrier layers was used. The electrolyte, which used $\mathrm{Co}$ (II) ion as a reducing agent, was composed of a mixture of $\mathrm{Ag}$ ion source solution $\left[4.5 \mathrm{mM} \mathrm{AgNO}_{3}, 0.45 \mathrm{M}\left(\mathrm{NH}_{4}\right)_{2} \mathrm{SO}_{4}\right.$, and 4.1 $\left.\mathrm{M} \mathrm{NH}_{4} \mathrm{OH}\right]$ and reducing agent solution $(45 \mathrm{mM}$ ethylenediaminetetraacetic acid, $90 \mathrm{mM}$ ethylenediamine and $45 \mathrm{mM}$ $\left.\mathrm{CoSO}_{4} \cdot 5 \mathrm{H}_{2} \mathrm{O}\right){ }^{26}$ Benzotriazole was added as a stabilizer. The $\mathrm{Ag}$ ion source and reducing agent solutions were mixed just before the $\mathrm{Ag}$ electroless plating experiment at a volumetric ratio of $2: 1$. Ag electroplating was conducted on the seed layer formed by electroless plating to evaluate the effect of conformality on electroplating. The detailed conditions of electroplating are described in our previous work. $^{14}$

The pretreatment of the substrate was performed as follows. First, the native oxide on the TiN surface was removed by immersion in a $1 \% \mathrm{HF}$ solution for $10 \mathrm{~min}$. After that, surface pretreatments, including $\mathrm{Sn}$ sensitization and $\mathrm{Pd}$ activation, were carried out. Sn sensitization was done using $\mathrm{SnCl}_{2} \cdot 2 \mathrm{H}_{2} \mathrm{O}$ and $\mathrm{HCl}$, and $\mathrm{Pd}$ activation was performed with a solution of $0.1 \mathrm{~g} / \mathrm{L} \mathrm{PdCl}_{2} \cdot 2 \mathrm{H}_{2} \mathrm{O}$, $3.0 \mathrm{~mL} / \mathrm{L} \mathrm{HCl}$, and $5.0 \mathrm{~mL} / \mathrm{L} \mathrm{HF}$. To determine the effect of $\mathrm{HF}, \mathrm{Pd}$ activation without HF was conducted on a Sn-sensitized substrate. Finally, the Ag film was deposited using electroless plating methods. The sample was rinsed in deionized water after each processing step. Morphologies of the Ag film and the activated surface were analyzed by a field emission scanning electron microscope (FESEM). The morphology of Pd clusters on the surface after activation was measured by an atomic force microscope (AFM) operating in tapping mode. Relative reflectance of the Ag film was obtained using a $\mathrm{He}-\mathrm{Ne}$ laser (wavelength: $632.8 \mathrm{~nm}$ ) and a photodiode. Optimization of Sn sensitization was performed by measuring (through a video microscope) the contact angles formed by dropping $0.01 \mathrm{~mL}$ water on the oxide-removed and Sn-sensitized TiN.

\section{Results and Discussion}

Effect of Sn sensitization.- To ascertain the effect of Sn sensitization on Pd activation and $\mathrm{Ag}$ electroless plating, the effects of three different types of pretreatment methods on Pd activation and subsequent catalytic layer formation of the $\mathrm{Ag}$ film were evaluated.

Figure 1 shows the surface morphology after pretreatment steps. In the case where $\mathrm{Sn}$ sensitization was applied prior to Pd activation, surface roughness was reduced by $\sim 40 \%$, which suggests that the preferred growth mode of Pd particles is two-dimensional (2D). The improved surface morphology may originate from the improved 


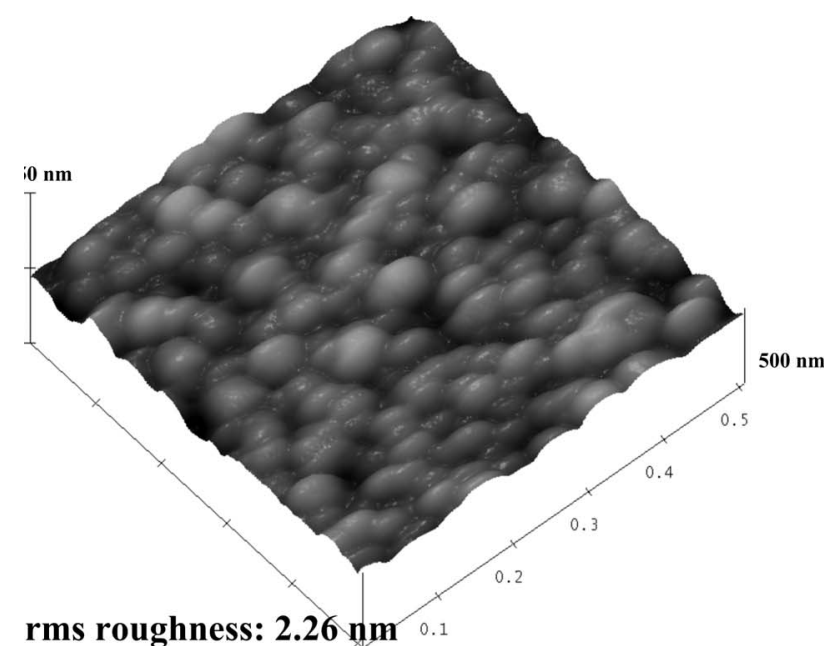

a)

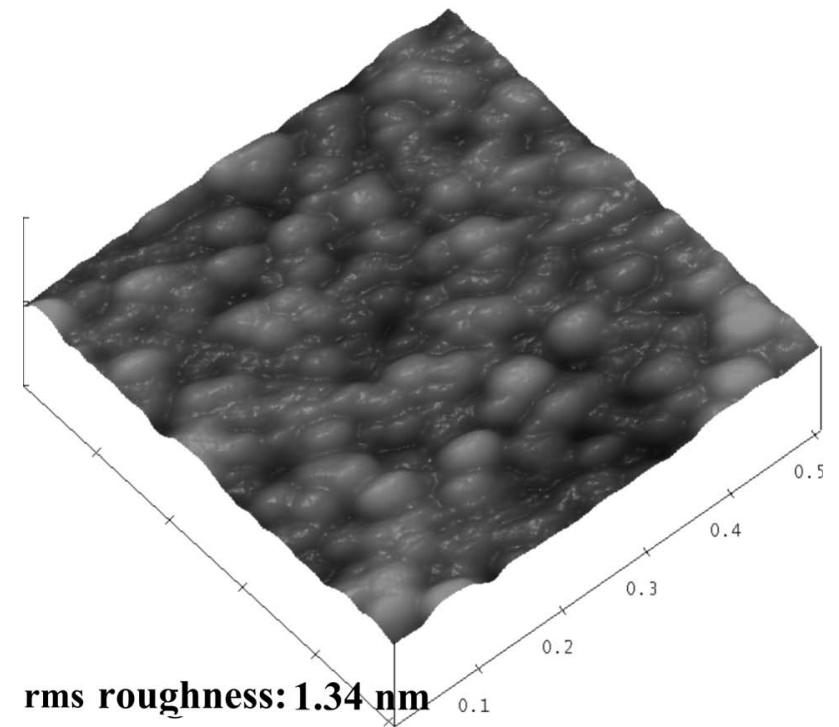

b)

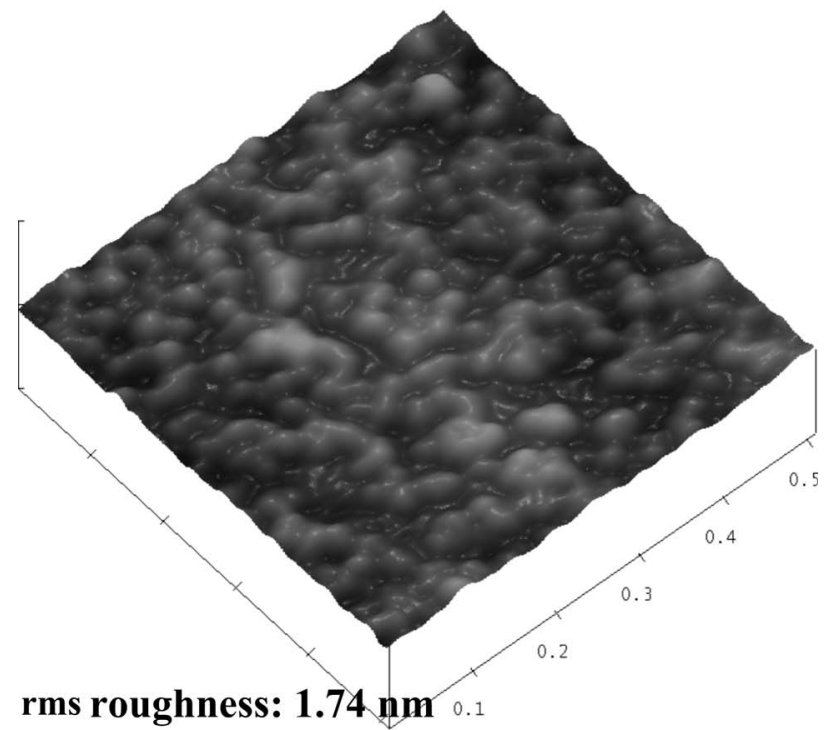

c)

Figure 1. AFM images of TiN substrate after (a) Pd activation only, (b) Sn sensitization and Pd activation, and (c) Sn sensitization and Pd activation without HF (scan size: $0.5 \times 0.5 \mu \mathrm{m}^{2}$, vertical scale: $50 \mathrm{~nm}$ ).

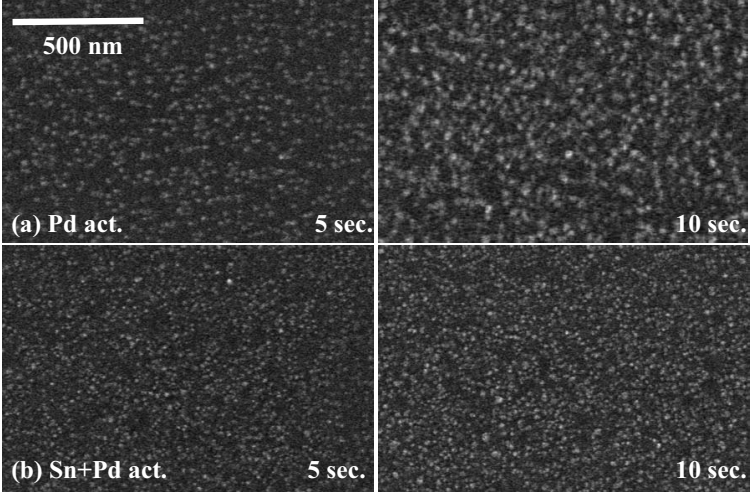

Figure 2. FESEM images of TiN surface after: (a) Pd activation only for 5 and $10 \mathrm{~s}$ and (b) Sn sensitization and Pd activation for 5 and $10 \mathrm{~s}$.

wetting properties of the TiN surface by Sn sensitization. The oxidation of the TiN surface in the activation solution may inhibit 2D growth of $\mathrm{Pd}$ particles without $\mathrm{Sn}$ sensitization, while the Snsensitized surface may support the growth of Pd particles in the horizontal direction by lowering the interfacial energy between the $\mathrm{Pd}$ and TiN substrate. ${ }^{23}$ When the activation solution without HF was used, the particles were more spherical than the other cases

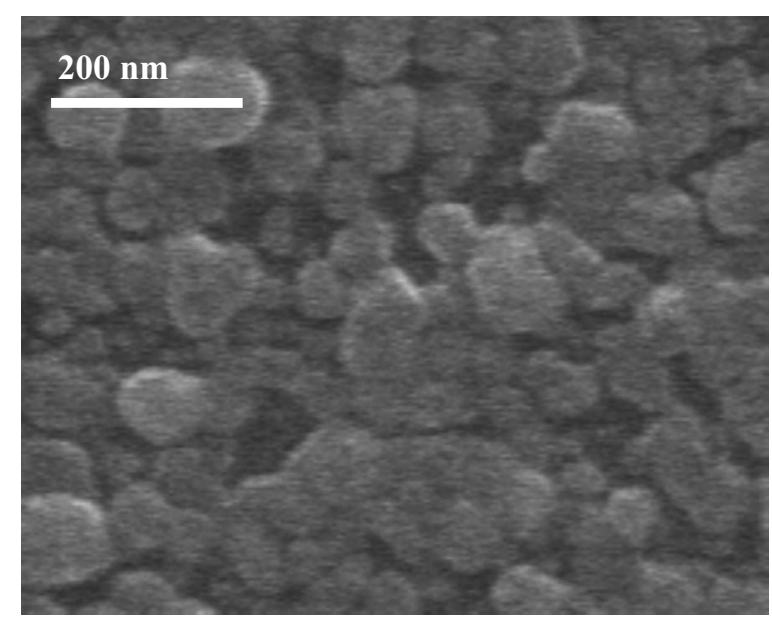

(a)

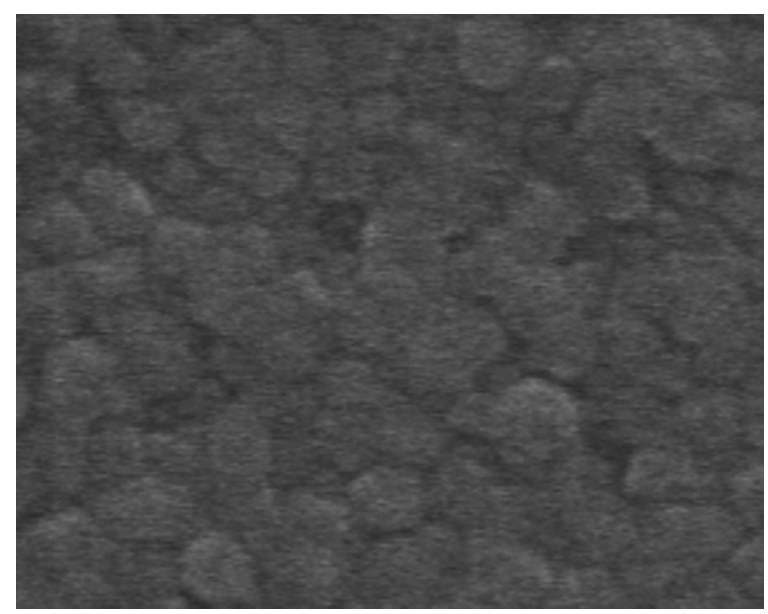

(b)

Figure 3. FESEM images after Ag electroless plating for $90 \mathrm{~s}$ after (a) Pd activation only and (b) Sn sensitization and Pd activation. 

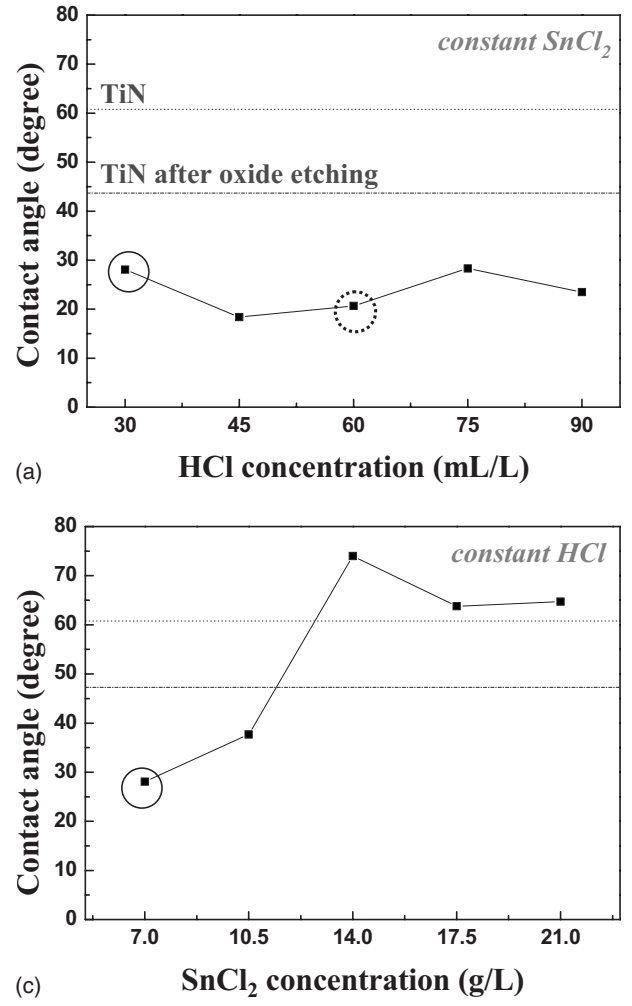
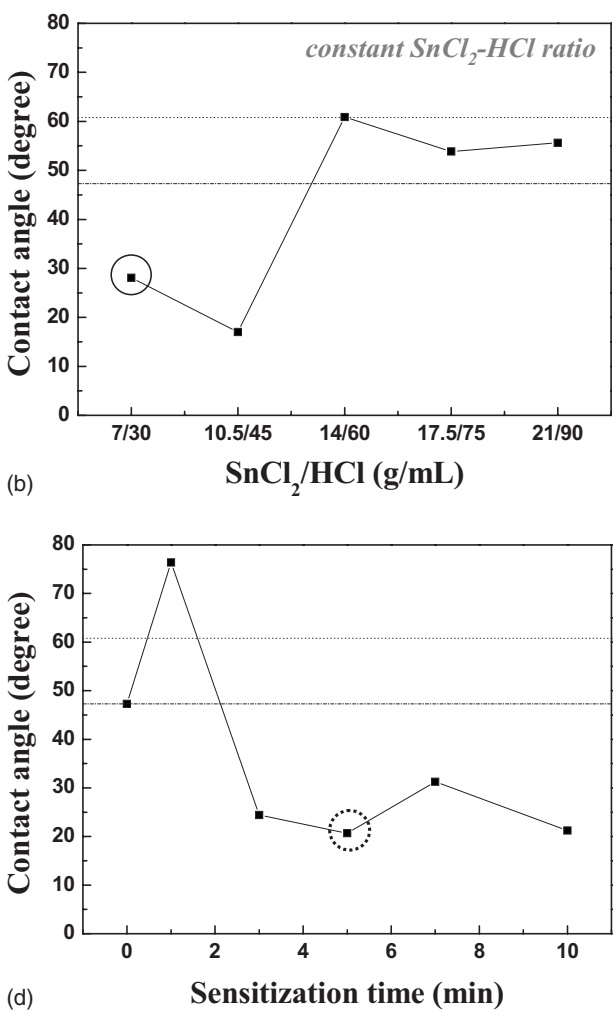

Figure 4. Contact angles over (a) change in the ratio of $\mathrm{SnCl}_{2}$ to $\mathrm{HCl}$, (b) change in the concentration of $\mathrm{HCl}$, (c) change in the concentration of $\mathrm{SnCl}_{2}$, and (d) change in the sensitization time (at $7.0 \mathrm{~g} / \mathrm{L} \mathrm{SnCl}_{2}$ and $60 \mathrm{~mL} \mathrm{HCl}$ ). Solid circles represent the starting condition $\left(7.0 \mathrm{~g} / \mathrm{L} \mathrm{SnCl}{ }_{2}\right.$ and $30 \mathrm{~mL} \mathrm{HCl}$ ). because the displacement reaction between $\mathrm{Sn}$ and $\mathrm{Pd}$ ions only occurred on the surface of the Sn particles. However, with the addition of HF, the displacement between $\mathrm{Sn}-\mathrm{Pd}$ and growth of Pd by oxidation of TiN seemed to occur simultaneously throughout the wafer surface. ${ }^{27}$ As shown in Fig. 2, the number of Pd clusters in the initial stage (after 5 s) was $\sim 70 \%$ higher on the Sn-sensitized TiN, which implies that both effects work simultaneously on the population of Pd particles. The initial stages of Ag growth $(90 \mathrm{~s}$ for deposition), before complete coalescence of clusters, are shown in Fig. 3, and boundaries between distinguishable Ag clusters were hardly observed with higher surface coverage, which shows that Ag clusters were growing in two dimensions on the $\mathrm{Sn}$ sensitized-Pd-activated TiN surface. After electroless plating for $90 \mathrm{~s}$, the sheet resistance of the Ag film was reduced by $\sim 80 \%$. Thus, Sn could effectively reduce the surface tension of the sample and improve the wetting properties thereby increasing the surface coverage of Pd particles.

Effect of changing the concentration of the Sn sensitization solution on the properties of Ag films. - The composition of the Sn sensitization solution on the oxide-removed TiN was optimized to improve hydrophilicity. When the concentrations of $\mathrm{HCl}$ and $\mathrm{SnCl}_{2}$ were modified to $60 \mathrm{~mL} / \mathrm{L}$ and $7 \mathrm{~g} / \mathrm{L}$, respectively, a lower contact angle was detected, as shown in Fig. 4. The modified Sn sensitization condition was applied to the pretreatment step, and Ag electroless plating was subsequently performed. Each AFM image in Fig. 5 was obtained after Ag electroless plating. Increasing the $\mathrm{HCl}$ concentration during $\mathrm{Sn}$ sensitization led to a more even $\mathrm{Ag}$ film with lower surface roughness. That is, the higher $\mathrm{HCl}$ content resulted in, on average, smaller Pd particles and a higher nucleation density, which was in agreement with the calculated sizes and densities of the Pd clusters for the Sn sensitization condition (Table I).

Figures 6 and 7 show the changes in both the sheet resistance and the relative reflectance of $\mathrm{Ag}$ thin films. As the growth of $\mathrm{Ag}$ clusters started from the discontinuous Pd clusters, some incubation time was required until they agglomerated and formed a continuous $\mathrm{Ag}$ film. Sn sensitization accelerated continuous film growth and decreased the sheet resistance sharply in the early stages of the deposition due to the improved wettability. Previously, it was reported that the affinity between $\mathrm{Ag}$ and $\mathrm{TiN}$ was so poor $^{28}$ that the decrease in interfacial energy between $\mathrm{Ag}$ and $\mathrm{TiN}$ from $\mathrm{Sn}$ sensitization would cause a significant difference in the growth mode of Ag clusters.

Electroless plating with optimized Sn sensitization was performed on a patterned TiN wafer, and Pd activation conditions were also modified to enhance the population of Pd clusters inside the trench to obtain higher step coverage. Two parameters, HF concentration and $\mathrm{Pd}-\mathrm{HCl}$ concentration, were varied. A slight increase in the $\mathrm{Pd}-\mathrm{HCl}$ complex concentration induced better step coverage coupled with a lower HF concentration $(1 \mathrm{~mL} / \mathrm{L}$ ) (Fig. 8 and 9). Pd activation without HF provided a step coverage of almost unity, but the surface roughness of the Ag film was much higher than that in the case with $1 \mathrm{~mL} / \mathrm{L}$ of $\mathrm{HF}$. The improvement in the step coverage with modifications to Pd and HF concentrations seems to show local suppression of Pd formation at the bottom of the trench due to the lack of reactant, but more intensive studies are necessary for a more comprehensive understanding of this observation.

Through the optimization of Pd activation conditions, a very thin and continuous Ag seed layer was deposited on a patterned TiN/Ti substrate as shown in Fig. 10a. The coverage of the sidewall of the electrolessly plated (ELP) seed layer was excellent in comparison to an Ag seed layer deposited by PVD (Fig. 10c). The thickness ratios of the bottom and sidewall to the top of the pattern after Ag electroplating under conformal electroplating conditions with a suppressor were both almost unity on the electroless plated seed layer (Fig. 10b). These results were better than those of the electroplated Ag film on the PVD seed layer shown in Fig. 10d. The thickness ratios of the sidewall and the bottom to the top sides were 0.71 and 0.64 , respectively, after electroplating of Ag on the PVD seed layer. 


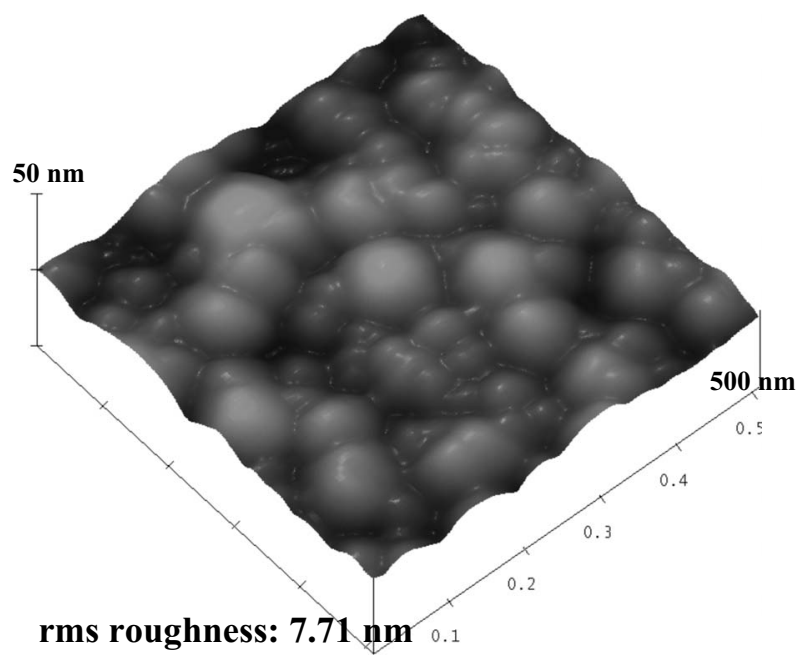

(a)

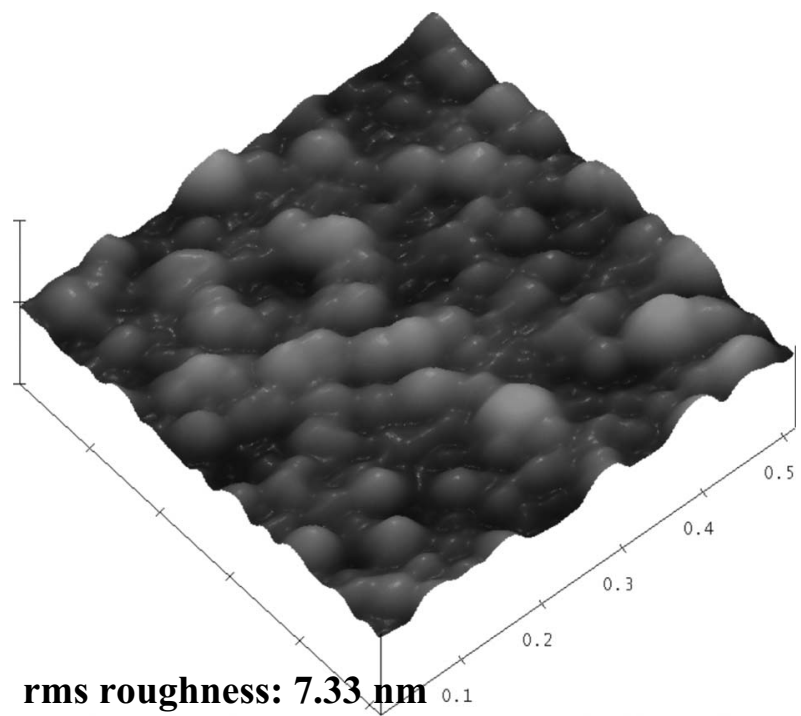

(b)

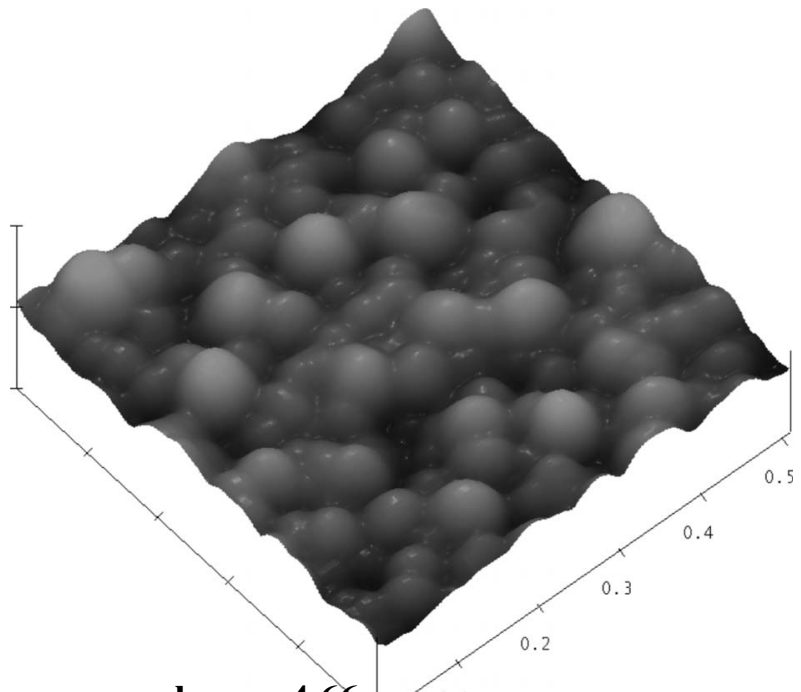

rms roughness: $4.66 \mathrm{~nm}^{0.1}$

(c)

Figure 5. AFM images after Ag electroless plating for $30 \mathrm{~s}$, when pretreatment methods are (a) Pd activation only, (b) Sn sensitization $\left(7 \mathrm{~g} / \mathrm{L} \mathrm{SnCl}{ }_{2}\right.$, $30 \mathrm{~mL} / \mathrm{L} \mathrm{HCl})$ and Pd activation, and (c) Sn sensitization $\left(7 \mathrm{~g} / \mathrm{L} \mathrm{SnCl}_{2}\right.$, $60 \mathrm{~mL} / \mathrm{L} \mathrm{HCl}$ ) and Pd activation (scan size: $0.5 \times 0.5 \mu^{2}$, vertical scale: $50 \mathrm{~nm})$.

\begin{tabular}{lccc}
\hline $\begin{array}{l}\text { Table I. Pd particles formed after Pd activation (before Ag elec- } \\
\text { troless plating). }\end{array}$ & & $\begin{array}{l}\text { Sn sensitization } \\
(30 \mathrm{~mL} / \mathrm{L} \mathrm{HCl})\end{array}$ & $\begin{array}{l}\text { Sn sensitization } \\
(60 \mathrm{~mL} / \mathrm{L} \mathrm{HCl})\end{array}$ \\
& $\begin{array}{c}\text { Pd activation } \\
\text { only }\end{array}$ & $\begin{array}{c}\mathrm{Pd} \text { activation } \\
+\mathrm{Pd} \text { activation }\end{array}$ \\
\hline $\begin{array}{l}\text { Pd particle area/ } \\
\text { total area }(\%)\end{array}$ & 47 & 47 & 47 \\
$\begin{array}{l}\mathrm{Pd} \text { particle density } \\
\left(/ \mu \mathrm{m}^{2}\right)\end{array}$ & 350 & 640 & 1910 \\
$\mathrm{~d}_{50}(\mathrm{~nm})$ & $48.9 \pm 0.3$ & $28.2 \pm 0.3$ & $16.1 \pm 0.1$
\end{tabular}

\section{Conclusions}

Sn sensitization resulted in improved Pd activation and Ag electroless plating for the production of thin Ag films. Sn sensitization prior to Pd activation and plating decreased the surface roughness of the Pd particles formed without significant changes in particle density, and the resulting growth mode of Pd particles was largely 2D. Furthermore, enhancement of the hydrophilic character of the substrate by modifying Sn sensitization conditions induced 2D growth of $\mathrm{Ag}$ in electroless plating, and faster formation of a continuous film was observed. These phenomena were hypothesized to result from the lower interfacial energy between the substrate and metal particles due to $\mathrm{Sn}$ sensitization. The Ag seed layer deposited by

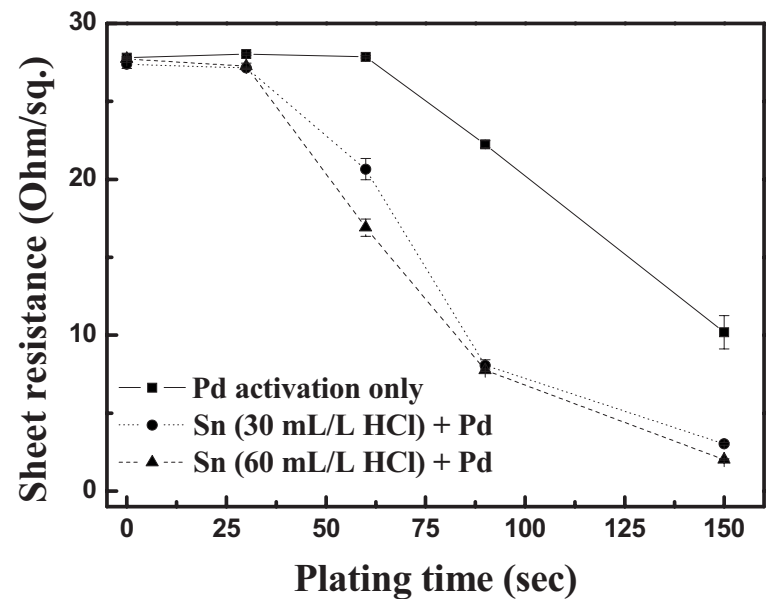

Figure 6. Changes in sheet resistances resulting from changes in the $\mathrm{Ag}$ electroless plating time according to the pretreatment method.

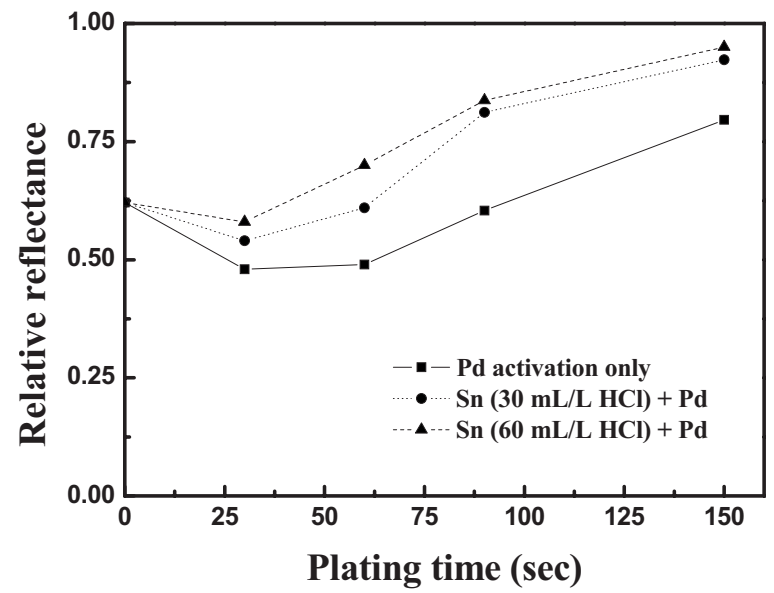

Figure 7. Changes of relative reflectance resulting from changes in the $\mathrm{Ag}$ electroless plating time according to the pretreatment method. 

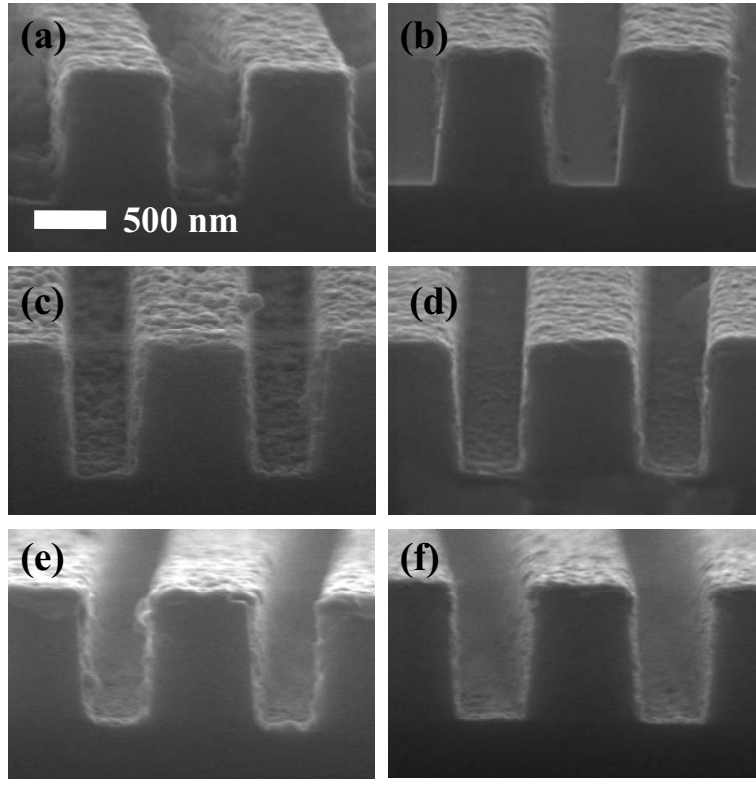

Figure 8. Cross-sectional FESEM images of electroless-deposited Ag films on a TiN surface, with modification of the Pd activation condition: (a) and (b) $0.1 \mathrm{~g} / \mathrm{L} \mathrm{PdCl}_{2}$, (c) and (d) $0.2 \mathrm{~g} / \mathrm{L} \mathrm{PdCl}_{2}$, (e) and (f) $0.4 \mathrm{~g} / \mathrm{L} \mathrm{PdCl}_{2}$. In all cases, the ratio between $\mathrm{PdCl}_{2}$ and $\mathrm{HCl}$ was fixed at $1 \mathrm{~g}$ to $30 \mathrm{~mL}$. (a), (c), (e) contained no HF while (b), (d), (f) contained $1 \mathrm{~mL} / \mathrm{L} \mathrm{HF}$.

electroless plating also showed better conformality performance as a seed layer for subsequent electroplating on a patterned structure.

\section{Acknowledgments}

This work was supported by KOSEF through the Research Center for Energy Conversion and Storage, and the Institute of Chemical Processing in Seoul National University.

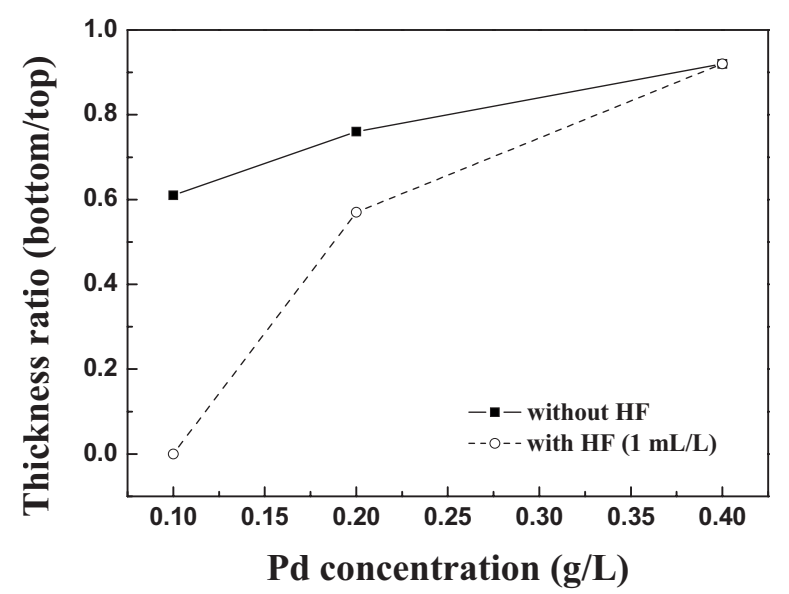

Figure 9. Changes in step coverage of the seed layers on the patterned TiN substrate with the Pd activation condition.
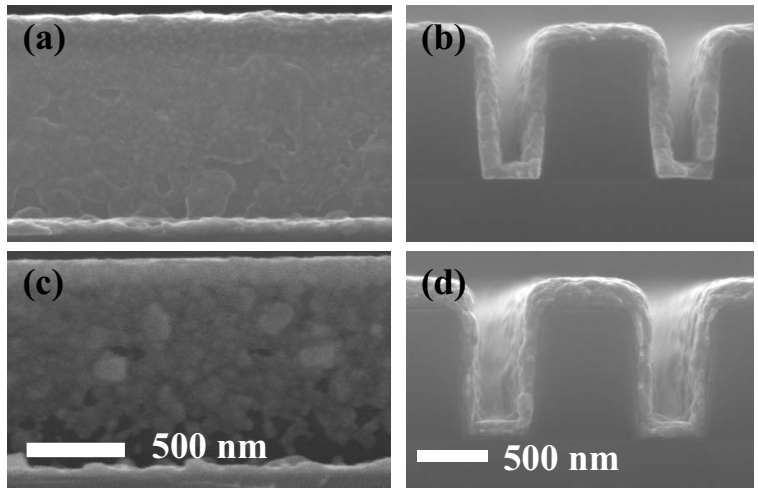

Figure 10. FESEM images of the sidewalls of the Ag seed layers: (a) electroless-plated seed layer, (c) PVD seed layer, and the cross-sectional FESEM images of the electroplated $\mathrm{Ag}$ films on the seed layers: (b) electroless-plated seed + electroplating, (d) PVD seed + electroplating.

Seoul National University assisted in meeting the publication costs of this article.

\section{References}

1. J. J. Kim and S. H. Cha, Jpn. J. Appl. Phys., Part 1, 40, 7151 (2001).

2. O. V. Zaplatynsky, Y. M. Prots, P. S. Salamakha, L. O. Muratova, and O. I. Bodak, J. Alloys Compd., 232, L1 (1996).

3. T. B. Massalski, Binary Alloy Phase Diagrams, 2nd ed., The Material International Society, Materials Park, Ohio (1990)

4. D. R. Lide, CRC Handbook of Chemistry and Physics, 81st ed., CRC Press, Boca Raton (2001).

5. Y. Okinaka and T. Osaka, Adv. Electrochem. Sci. Eng., 3, 55 (1994)

6. G. W. N. White and J. R. de Bruyn, Physica A, 239, 166 (1997).

7. H. T. Ng and S. F. Y. Li, J. Electrochem. Soc., 145, 3301 (1998).

8. F. Caturla, F. Molina, M. Molina-Sabio, and F. Rodriguez-Reinoso, J. Electrochem. Soc., 142, 4084 (1995).

9. C. R. K. Rao and M. Pushpavanam, Mater. Chem. Phys., 68, 62 (2001).

10. I. Ohno, Mater. Sci. Eng., A, 146, 33 (1991).

11. E. Touchais-Papet, M. Charbonnier, and M. Romand, Appl. Surf. Sci., 138, 557 (1999).

12. Y. Shacham-Diamand and S. Lopatin, Electrochim. Acta, 44, 3639 (1999).

13. A. Maleki and A. Micek-Ilnicka, Surf. Coat. Technol., 123, 72 (2000).

14. E. J. Ahn and J. J. Kim, Electrochem. Solid-State Lett., 7, C118 (2004).

15. B. C. Baker, C. Witt, D. Wheeler, D. Josell, and T. P. Moffat, Electrochem. SolidState Lett., 6, C67 (2003)

16. C. H. Lee and J. J. Kim, J. Vac. Sci. Technol. B, 23, 475 (2005)

17. C. Longo, P. T. A. Sumodjo, and F. Sanz, J. Electrochem. Soc., 144, 1659 (1997).

18. T. Osaka and J. Takematsu, J. Electrochem. Soc., 127, 1021 (1980).

19. N. Feldstein and J. A. Weiner, J. Electrochem Soc, 120, 475 (1973).

20. C. H. de Minjer and P. F. J. v. d. Boom, J. Electrochem. Soc., 120, 1644 (1973).

21. N. Feldstein, M. Schlesinger, N. E. Hedgecock, and S. L. Chow, J. Electrochem. Soc., 121, 738 (1974)

22. M. Schlesinger and J. Kisel, J. Electrochem. Soc., 136, 1658 (1989).

23. H.-H. Hsu, C.-W. Teng, S.-J. Lin, and J.-W. Yeh, J. Electrochem. Soc., 149, C143 (2002).

24. T. O. Drews, A. Rasdisic, J. Erlebacher, R. D. Braatz, P. C. Searson, and R. C. Alkire, J. Electrochem. Soc., 153, C434 (2006).

25. E. Budevski, G. Staikov, and W. J. Lorenz, Electrochemical Phase Formation and Growth, VCH Verlagsgesellshaft mbH, Weinheim (1996).

26. H.-C. Koo and J. J. Kim, J. Electrochem. Soc., 155, D176 (2008).

27. Y. Wu, W. C. Chen, H. P. Pong, C. C. Wan, and Y. Y. Wang, J. Electrochem. Soc., 149, G309 (2002).

28. P. Xiao and B. Derby, Acta Mater., 44, 307 (1996). 